\title{
Analysis of Annual Maximum Rainfall Series using Method of L- Moments in Some Selected Sites in South-South Geographical Zone, Nigeria
}

\author{
I. R. Ilaboya ${ }^{\text {a, * }}$, E. A. Otuaro ${ }^{b}$ \\ ${ }^{a}$ Department of Civil Engineering, University of Benin, P.M.B. 1154, Benin City, Nigeria \\ ${ }^{b}$ Department of Civil Engineering, Nigeria Maritime University, Okerenkoko, Delta State, Nigeria
}

Authors' Contributions

This work was carried out in collaboration between authors. The revised manuscript was read and approved by all authors.

\section{ARTICLE INFO}

Article history:

Received 2 December 2020

Received in revised form

17 December 2020

Accepted 18 December 2020

Available online

31 December 2020

Keywords:

Goodness of fit statistics

Homogeneity test

L-moments

Probability distribution

\begin{abstract}
Determination of the extent of peak rainfall for different return periods is an essential ingredient for the accurate design of hydraulic structures such as drains, dams and culverts as well as detection of flood risk areas. The focus of this study is to analyze annual maximum daily rainfall series in some selected sites within the coastal region of Nigeria using three parameter probability distribution models, namely, Generalized Logistics (GLO), Generalized Extreme Value (GEV) and Generalized Pareto (GPA) with the view of identifying the best fit probability distribution model per station that can be employed to estimate the rainfall magnitude for selected return periods. Specific time series analysis test, namely, detection of outlier and homogeneity test were performed to certify that the data utilized are adequate and suitable. Descriptive statistics such as sample mean, variance, standard deviation, kurtosis, skewness, and coefficient of variation were computed using basic statistical equations. The probability weighted moment parameters $\left(b_{0}, b_{1}, b_{2}\right.$ and $\left.b_{3}\right)$, Lmoment values $\left(\lambda_{1}, \lambda_{2}, \lambda_{3}\right.$ and $\left.\lambda_{4}\right)$ and ratios $\left(\tau_{2}, \tau_{3}\right.$ and $\left.\tau_{4}\right)$ including the distribution parameters, namely, shape $(\mathrm{k})$, scale $(\alpha)$ and location $(\xi)$ parameters were computed based on L-moments procedures. To select the best-fit probability distribution model per station, carefully chosen goodness-of-fit statistics, namely, root mean square error, relative root mean square error, maximum absolute deviation index, maximum absolute error and probability plot correlation coefficient were employed since they can adequately assess the fitted distribution at a site. Results obtained indicate that the GLO is the best fit distribution for analyzing annual maximum daily rainfall series from Warri and Calabar while GPA for Port Harcourt and Uyo.
\end{abstract}

https://doi.org/10.37121/ijesr.v1.146

\section{Introduction}

In many countries of the world, flood arising from high precipitations are causing damages to properties and agricultural lands resulting in huge economic losses including loss of lives within the affected areas [1]. Precipitations can be estimated through the use of different techniques depending upon the structure being analyzed or designed, and size of watershed. Methodologies to precipitation hydrology include

\footnotetext{
* Corresponding author

E-mail address: rudolph.ilaboya@uniben.edu
}

2756-6773 / (C) 2020 the authors. Published by Sciengtex. This is an open access article under CC BY-NC-ND license (http://creativecommons.org/licenses/by-nc-nd/4.0/) 
probabilistic, deterministic, conceptual or parametric analysis [2]. The reasonable valuation of precipitation has remained a main challenging concern where hydrological data and information are inadequate. This is the typical case in many gauging stations in Nigeria where most of the sites are poorly gauged or not gauged at all. Estimation of precipitations must be fairly accurate not only to prevent catastrophes, but also to avoid excessive costs due to overestimation of precipitation magnitude, or excessive damage while underestimating the precipitation potential. Determination and accurate analysis of extreme flood discharge requires the utilization of statistical frequency analysis or fitting of probability distribution to the series of observed annual maximum discharge [3]-[5]. Univariate statistics is one of the mostly used statistical techniques employed for rainfall frequency analysis. Apart from this, univariate statistics has also find used in characterizing rainfall, analysis of peak discharge series including low flow record of observations [6].

Numerous probability distribution models needed for precipitation frequency analysis exist in the literature of hydrology. Examples of such probability distribution models include; Generalized Logistics (GLO), Generalized Pareto (GPA), Generalized Extreme Value (GEV), Normal distribution and Gumbel distribution [7]. To apply any probability distribution model for precipitation frequency analysis, the parameters of such probability distribution model must first be approximated. To predict the parameters of a specific probability distribution model, different methods applied, namely, Least Square Regression (LSR), Method of Moments (MoM), Maximum Likelihood Estimation (MLE) and method of L-moments (LMO). Owing to the limitations of LSR, MLE and MoM, LMO was proposed to precisely estimate the parameters of probability distributions. L-Moment is an enhanced advancement over typical product moment statistics for characterizing the shape of a probability distribution and estimating the distribution parameters, particularly for environmental data where sample sizes are commonly very small [1],[8]-[10].

\section{L-Moment Theory and Statistics}

The basic steps involved in the analysis of rainfall frequency by method of L-Moment as prescribed by [1], [11] are described in this paper.

\subsection{Computation of Probability Weighted Moments}

PWM is essential for LMO computations. To compute the PWM, the data employed must be ranked in ascending order of magnitude. The basic equations involved are:

$b_{0}=\frac{1}{N} \sum_{j=1}^{n} X_{(j: n)}$.

$b_{1}=\frac{1}{N} \sum_{j=2}^{n} X_{(j: \mathrm{n})}[(j-1) /(n-1)]$.

$b_{2}=\frac{1}{N} \sum_{j=3}^{n} X_{(j: \mathrm{n})}[(\mathrm{j}-1)(\mathrm{j}-2)] /[(\mathrm{n}-1)(\mathrm{n}-2)]$.

$b_{3}=\frac{1}{N} \sum_{j=4}^{n} X_{(j: \mathrm{n})}[(\mathrm{j}-1)(\mathrm{j}-2)(\mathrm{j}-3)] /[(\mathrm{n}-1)(\mathrm{n}-2)(\mathrm{n}-3)]$.

Where; $X_{(\mathrm{j})}$ is the ranked annual maximum series, $X_{(1)}$ is the smallest precipitation or stream flow data and $X_{(\mathrm{n})}$ is the largest.

\subsection{Computation of L-Moment Values}

LMOs are normally calculated in terms of PWMs. The following equations define the first four Lmoment values [1]:

$\lambda_{1}=L_{1}=b_{0}$.

$\lambda_{2}=L_{2}=\left(2 b_{1}-b_{0}\right)$.

$\lambda_{3}=L_{3}=\left(6 b_{2}-6 b_{1}+b_{0}\right)$.

$\lambda_{4}=L_{4}=\left(20 b_{3}-30 b_{2}+12 b_{1}-b_{0}\right)$.

\subsection{Computation of L-Moment Ratio}

To compute the LMO ratios, the following equations prescribed by [1] applies:

$L-C V$ (Coefficient of variability) $=\left(\tau_{2}\right)$

$L-$ Skewness $=\left(\tau_{3}\right)$

$L-$ Kurtosis $=\left(\tau_{4}\right)$ 
$L-C V$ is a measure of variability, which is usually in the range of $0<|L-C V|<1$. According to [12], [13], negative values of $L-C V$ are only possible if the at-site mean has a negative value. It is a dimensionless quantity. L-Skewness is a measure of asymmetry, which may take positive or negative values. It is in the range $0<\mid \mathrm{L}-$ Skewness $\mid<1$ according to [14].

L-kurtosis is a measure of the "peakedness" of the probability distribution of a real-valued random variable. To compute the parameters $\left(\tau_{2} \tau_{3}\right.$ and $\left.\tau_{4}\right)$, the equations proposed by [1], [15] apply:

$\tau_{2}=\frac{\lambda_{2}}{\lambda_{1}}=\frac{L_{2}}{L_{1}}$.

$\tau_{3}=\frac{\lambda_{3}}{\lambda_{2}}=\frac{L_{3}}{L_{2}}$.

$\tau_{4}=\frac{\lambda_{4}}{\lambda_{3}}=\frac{L_{4}}{L_{3}}$

\section{Materials and Methods}

\subsection{Description of Study Area}

The six geopolitical zones in Nigeria are major divisions in modern Nigeria, which were not created based on geopolitical location, but rather, they were created on the bases of states with similar cultural characteristics, ethnic diversity and historical background. The south-south geopolitical zone comprises six states, as shown in Fig. 1. The entire south-south geopolitical zone occupies a land mass of approximately 85,303 $\mathrm{km}^{2}$. The 2006 National Population Census put the population of the region at $21,014,655$ according to [16]. With reference to Fig. 1, the region is strategically positioned at the point where the ' $Y$ ' tail of the river Niger joins the Atlantic Ocean through the Gulf of Guinea. For this study, four selected states within the south-south region were used and they include Akwa-Ibom, Cross River, Delta and Rivers. The states were selected on the bases of data availability.

\subsection{Data Collection/Preliminary Analysis}

The data utilized for this study, which include daily precipitation datasets for 40 years spanning between 1974 and 2013 was collected from the Nigerian Meteorological Agency, Oshodi, Nigeria. To analyze the data and obtain the annual maximum daily precipitation records, Microsoft excel program was employed. To ascertain the data quality, selected preliminary analysis were done. Some of the preliminary analysis includes; outlier detection and test of homogeneity. For frequency analysis, it is expected that the data be homogeneous and independent. Homogeneity test, which is based on the cumulative deviation from the mean was carried out to establish that the data used are from the same population distribution. The following equations were employed to define the assumption of homogeneity [17]:

$S_{k}=\sum_{i=1}^{k}\left(X_{i}-\bar{X}\right) \mathrm{k}=1, \ldots, \mathrm{n}$.

Where, $X_{i}$ represents the record for the series $X_{1}, X_{2} \ldots, X_{\mathrm{n}} ; \bar{X}$ is the mean while $S_{\mathrm{ks}}$ is the residual mass curve.

For a homogeneous record, one may expect that the $S_{\mathrm{ks}}$ fluctuate around zero in the residual mass curve since there is no systematic pattern in the deviation of $X_{\mathrm{i}}$. To perform the homogeneity test, a software package (Rainbow) for analyzing hydrological data was employed.

\subsection{Fitting of Probability Distribution Models}

The three probability distribution models employed for this analysis are GEV, GLO and GPA. The fundamental equations of the selected probability distribution model are presented in Table 1. 
Table 1 Basic Equations of selected probability distribution models [1]

\begin{tabular}{|c|c|c|c|c|}
\hline Distribution & Parameters/Range & $\begin{array}{l}\text { Probability density } \\
\text { function } \mathrm{f}(\mathrm{x})\end{array}$ & $\begin{array}{l}\text { Cumulative distribution function } \\
\mathrm{F}(\mathrm{x})\end{array}$ & Quantile function $\left(\mathrm{x}_{\mathrm{p}}\right)$ \\
\hline GEV & $\begin{array}{c}\text { Parameters: } \\
\xi \text { (location), } \alpha \text { (scale), } \mathrm{k}(\text { shape }) \\
\text { Range: } \alpha>0 \\
\xi+\alpha / \mathrm{k} \leq \mathrm{x}<\infty \text { for } \mathrm{k}<0 \\
-\infty \leq \mathrm{x} \leq \xi+\alpha / \mathrm{k} \text { for } \mathrm{k}>0\end{array}$ & $f(x)=\frac{1}{\alpha}\left[1-\frac{k(x-\xi)}{\alpha}\right]^{1 / k-1} \exp \left\langle-\left[1-\frac{k(x-\xi)}{\alpha}\right]^{1 / k}\right\}$ & $F(x)=\exp \left(-\left[1-\frac{k(x-\xi)}{\alpha}\right]^{1 / k}\right)$ & $x_{p}=\xi+\frac{\alpha}{k}\left(1-[-\ln (F)]^{k}\right)$ \\
\hline GPA & $\begin{array}{c}\text { Parameters: } \\
\xi \text { (location), } \alpha \text { (scale), } \mathrm{k}(\text { shape }) \\
\text { Range: } \alpha>0, \xi \leq \mathrm{x}<\infty \text { for } \mathrm{k}<0, \xi \\
\leq \mathrm{x} \leq \xi+\alpha / \mathrm{k} \text { for } \mathrm{k}>0\end{array}$ & $f(x)=\frac{1}{\alpha}\left[1-k \frac{x-\xi}{\alpha}\right]^{1 / k-1}$ & $F(x)=1-\left[1-k \frac{x-\xi}{\alpha}\right]^{1 / k}$ & $x_{p}=\xi+\frac{\alpha}{k}\left[1-(1-F)^{k}\right]$ \\
\hline GLO & $\begin{array}{l}\text { Parameters: } \\
\begin{array}{l}\xi \text { (location), } \alpha \text { (scale), } \mathrm{k}(\text { shape }) \\
\text { Range: }\end{array} \\
\begin{array}{c}\alpha>0, \xi+\alpha / \mathrm{k} \leq \mathrm{x}<\infty \text { for } \mathrm{k}<0,-\infty \\
\leq \mathrm{x} \leq \xi+\alpha / \mathrm{k} \text { for } \mathrm{k}>0\end{array}\end{array}$ & $\begin{array}{l}\gamma=\left\lceil 1-\frac{k(x-\xi}{\alpha}\right]^{\frac{1}{K}} \text { for } \mathrm{k} \stackrel{\neq}{0}_{0} \\
f_{x}=\left(\frac{1}{\alpha}\right)\left[\frac{\gamma^{(1-x)}}{(1+\gamma)}\right]^{2}\end{array}$ & $F_{x}(x)=\frac{1}{1+\gamma}$ & $x_{p}=\xi+\frac{\alpha}{k}\left[1-\left(\frac{1-F}{F}\right)^{k}\right]$ \\
\hline
\end{tabular}




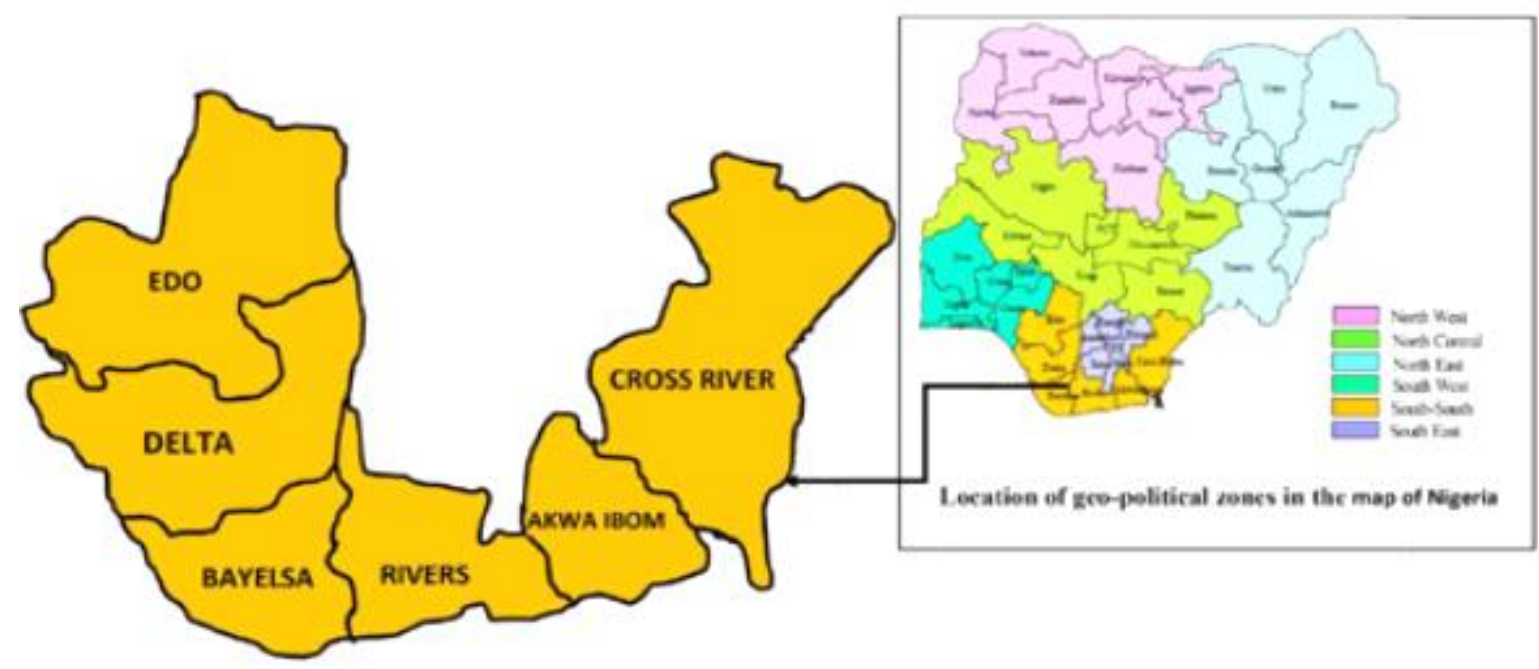

Fig. 1 Map of South-South Geopolitical Zone in Nigeria.

\subsection{Selection of Best Fit Probability Distribution Model}

The probability distribution model that best fit the annual maximum daily rainfall data was selected based on five Goodness-of-Fit (GoF) statistics presented in Table 2. The GoF was selected based on their potential to summarize the deviation between observed and estimated precipitation. Also, they are able to adequately evaluate the fitted distribution at a station.

Table 2 Selected goodness of fit statistics [1].

\begin{tabular}{cc}
\hline \hline Statistics & Equation \\
\hline Root Mean Squared Error (RMSE) & $R M S E=\left(\frac{\sum\left(x_{i}-y_{i}\right)^{2}}{n-m}\right)^{1 / 2}$ \\
Relative Root Mean Squared Error (RRMSE) & $R R M S E=\left(\frac{\sum\left(\frac{x_{i}-y_{i}}{x_{i}}\right)^{2}}{n-m}\right)^{1 / 2}$ \\
Mean Absolute Deviation Index (MADI) & $M A D I=\frac{1}{N} \sum_{i=1}^{N}\left|\frac{x_{i}-y_{i}}{x_{i}}\right|$ \\
Maximum Absolute Error (MAE) & MAE $=\max \left(\left|x_{i}-y_{i}\right|\right)$ \\
Probability Plot Correlation Coefficient & PPCC $=\frac{\sum\left[\left(x_{i}-\bar{x}\right)\left(y_{i}-\bar{y}\right)\right]}{\left[\sum\left(x_{i}-x\right)^{2} \Sigma\left(y_{i}-\bar{y}\right)^{2}\right]^{1 / 2}}$ \\
\hline \hline
\end{tabular}

\section{Results and Discussion}

Results of homogeneity test, which was employed to justify that the data used for this study and the results are presented in Fig. 2. Results of Fig 2, showed that the data used are statistically homogeneous since the data points fluctuate around the center line of the residual mass curve. This result agrees with the findings presented in [6], [8]. The descriptive and LMO statistics, which includes; the PWM statistics $\left(b_{0}, b_{1}, b_{2}\right.$ and $\left.b_{3}\right)$, computed L-moment values $\left(\lambda_{1}, \lambda_{2}, \lambda_{3}\right.$ and $\left.\lambda_{4},\right)$ and the LMO ratio values for the selected stations are presented in Table 3 .

The LMO parameters $\lambda_{1}$ and $\lambda_{2}$ their ratio $\left(\tau=\lambda_{2} / \lambda_{1}\right)$ termed L-CV, and L-moment ratios $\lambda_{3}$ and $\lambda_{4}$ are the most valuable quantities for summarizing probability distribution [18]. The parameters of location $(\xi)$, scale $(\alpha)$ and shape $(\mathrm{k})$ for the selected probability distribution models are given in Table 4. 


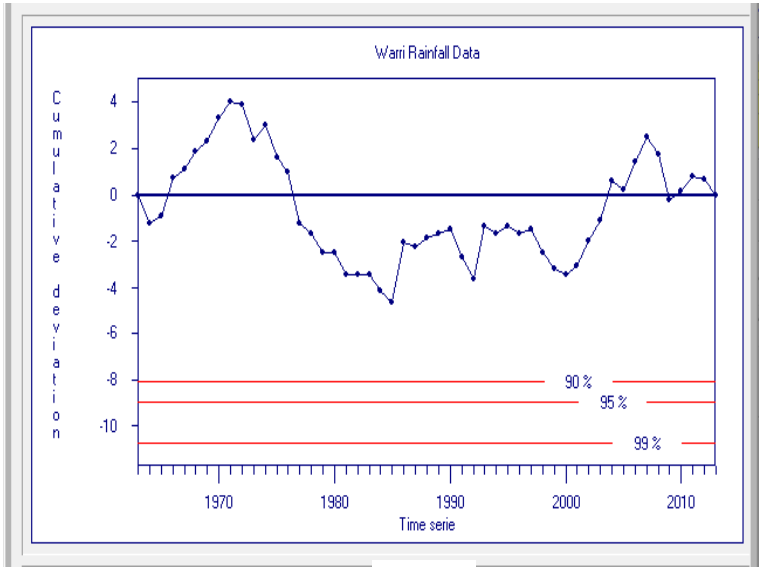

(a)

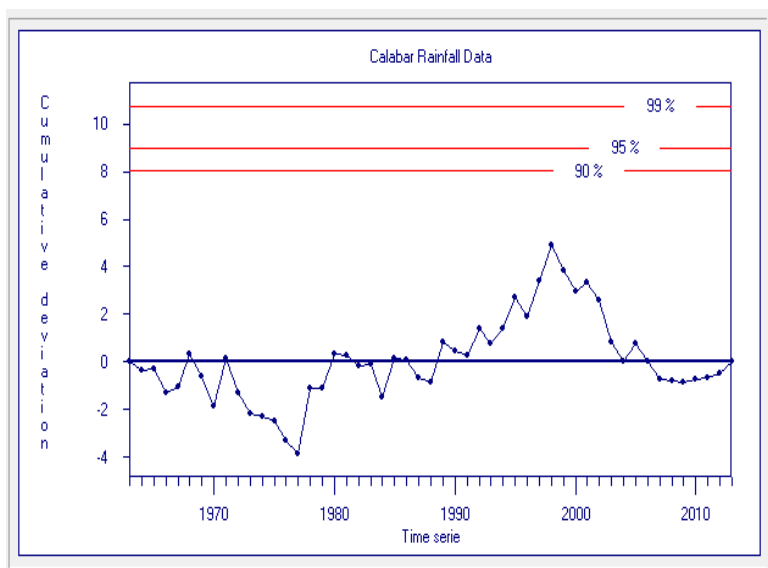

(c)

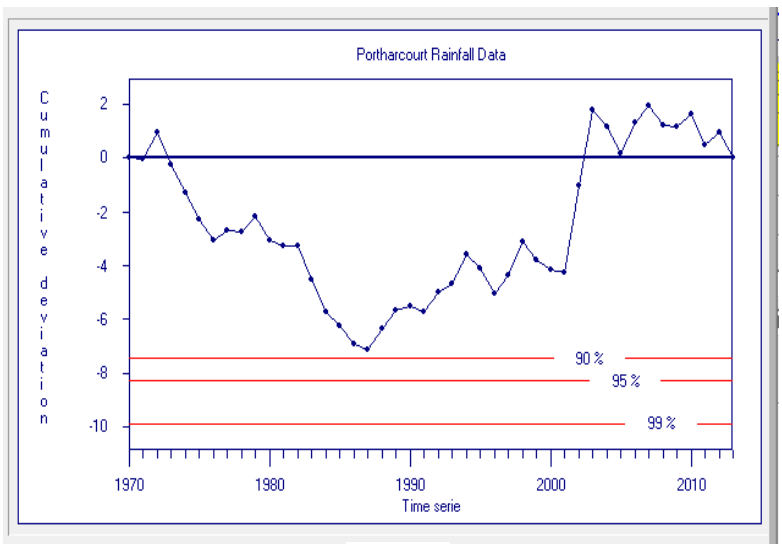

(e)

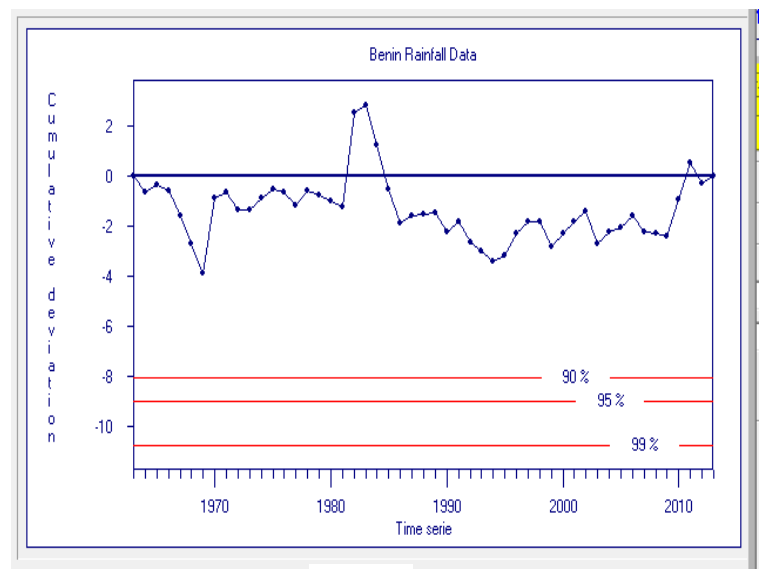

(b)

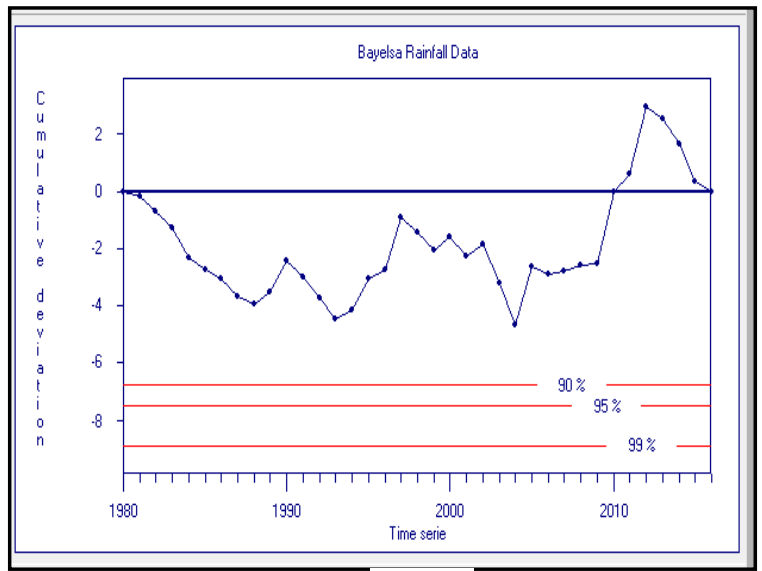

(d)

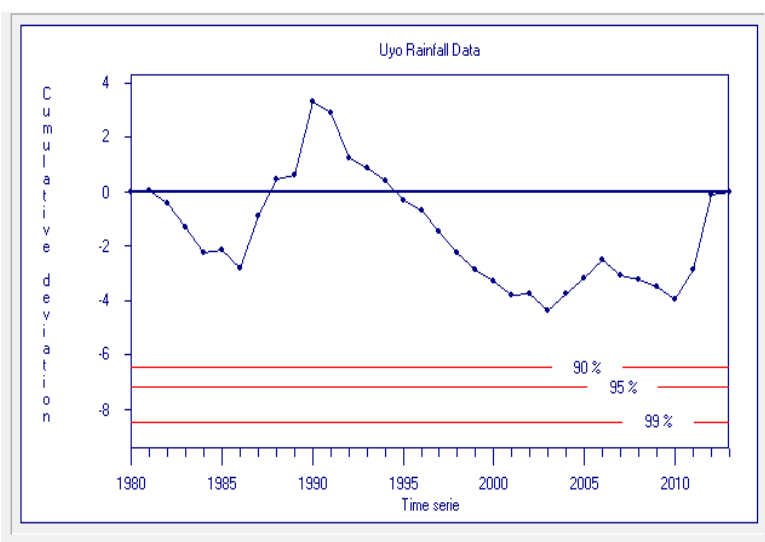

(f)

Fig. 2 Homogeneity test for (a) Warri Data (b) Benin Data (c) Calabar Data (d) Bayelsa data (e) PHC Data (f) Uyo Data. 
Table 3 Descriptive and L-moment statistics for study area.

\begin{tabular}{|c|c|c|c|}
\hline $\begin{array}{l}\text { Probability Weighted } \\
\text { Moment Values }\end{array}$ & L-Moment Values & L-Moment Ratios & Basic Statistics \\
\hline \multicolumn{4}{|l|}{ Warri } \\
\hline $\mathrm{b}_{0}=115.375$ & $\lambda_{1}=115.375$ & $\mathrm{~L}-\mathrm{CV}=0.123$ & $\mathrm{n}=40$ \\
\hline$b_{1}=64.783$ & $\lambda_{2}=14.191$ & L-Skewness $=0.095$ & Mean $=115.375$ \\
\hline $\mathrm{b}_{2}=45.779$ & $\lambda_{3}=1.347$ & L-Kurtosis $=0.195$ & Variance $=651.332$ \\
\hline \multirow[t]{4}{*}{$\mathrm{b}_{3}=35.705$} & $\lambda_{4}=2.763$ & & Standard Dev. $=25.521$ \\
\hline & & & C.V $=0.221$ \\
\hline & & & Skewness $=0.508$ \\
\hline & & & Kurtosis $=0.789$ \\
\hline \multicolumn{4}{|l|}{ Benin } \\
\hline $\mathrm{b}_{0}=88.125$ & $\lambda_{1}=88.125$ & $\mathrm{~L}-\mathrm{CV}=0.1139$ & $\mathrm{n}=40$ \\
\hline$b_{1}=49.0822$ & $\lambda_{2}=10.0395$ & L-Skewness $=0.0442$ & Mean $=88.125$ \\
\hline $\mathrm{b}_{2}=34.4688$ & $\lambda_{3}=0.4441$ & L-Kurtosis $=0.26684$ & Variance $=377.7855$ \\
\hline \multirow[t]{4}{*}{$\mathrm{b}_{3}=26.7940$} & $\lambda_{4}=2.6789$ & & Standard Dev. $=19.4367$ \\
\hline & & & C.V $=0.22056$ \\
\hline & & & Skewness $=1.2796$ \\
\hline & & & Kurtosis $=5.1694$ \\
\hline \multicolumn{4}{|l|}{ Calabar } \\
\hline $\mathrm{b}_{0}=126.645$ & $\lambda_{1}=126.645$ & $\mathrm{~L}-\mathrm{CV}=0.14058$ & $\mathrm{n}=40$ \\
\hline$b_{1}=72.2247$ & $\lambda_{2}=17.8044$ & L-Skewness $=0.16247$ & Mean $=126.645$ \\
\hline $\mathrm{b}_{2}=51.5993$ & $\lambda_{3}=2.8928$ & L-Kurtosis $=0.14656$ & Variance $=1024.63$ \\
\hline$b_{3}=40.5269$ & $\lambda_{4}=2.6093$ & & Standard Dev. $=32.0099$ \\
\hline & & & C.V $=0.25275$ \\
\hline & & & Skewness $=0.7293$ \\
\hline & & & Kurtosis $=0.3654$ \\
\hline \multicolumn{4}{|l|}{ Port Harcourt } \\
\hline $\mathrm{b}_{0}=99.4925$ & $\lambda_{1}=99.4925$ & $\mathrm{~L}-\mathrm{CV}=0.1437$ & $\mathrm{n}=40$ \\
\hline $\mathrm{b}_{1}=56.8934$ & $\lambda_{2}=14.2943$ & L-Skewness $=0.2116$ & Mean $=99.4925$ \\
\hline $\mathrm{b}_{2}=40.8155$ & $\lambda_{3}=3.0252$ & L-Kurtosis $=0.1315$ & Variance $=705.829$ \\
\hline$b_{3}=32.1558$ & $\lambda_{4}=1.8796$ & & Standard Dev. $=26.567$ \\
\hline & & & $\mathrm{C} . \mathrm{V}=0.2670$ \\
\hline & & & Skewness $=1.3296$ \\
\hline & & & Kurtosis $=2.4014$ \\
\hline \multicolumn{4}{|l|}{ Uyo } \\
\hline $\mathrm{b}_{0}=100.225$ & $\lambda_{1}=100.225$ & $\mathrm{~L}-\mathrm{CV}=0.1691$ & $\mathrm{n}=40$ \\
\hline$b_{1}=58.5865$ & $\lambda_{2}=16.9479$ & L-Skewness $=0.2796$ & Mean $=100.225$ \\
\hline $\mathrm{b}_{2}=42.6722$ & $\lambda_{3}=4.7391$ & L-Kurtosis $=0.20799$ & Variance $=1162.915$ \\
\hline $\mathrm{b}_{3}=34.0439$ & $\lambda_{4}=3.5251$ & & Standard Dev. $=34.1015$ \\
\hline & & & C. $V=0.3402$ \\
\hline & & & Skewness $=2.2727$ \\
\hline & & & Kurtosis $=8.0068$ \\
\hline \multicolumn{4}{|l|}{ Bayelsa } \\
\hline $\mathrm{b}_{0}=87.95$ & $\lambda_{1}=87.95$ & $\mathrm{~L}-\mathrm{CV}=0.1987$ & $\mathrm{n}=40$ \\
\hline $\mathrm{b}_{1}=52.7109$ & $\lambda_{2}=17.4717$ & L-Skewness $=0.4799$ & Mean $=87.95$ \\
\hline $\mathrm{b}_{2}=39.4500$ & $\lambda_{3}=8.3847$ & L-Kurtosis $=0.3670$ & Variance $=1686.261$ \\
\hline $\mathrm{b}_{3}=32.2666$ & $\lambda_{4}=6.4119$ & & Standard Dev. $=41.0641$ \\
\hline & & & C. $V=0.4669$ \\
\hline & & & Skewness $=3.0959$ \\
\hline & & & Kurtosis $=11.1832$ \\
\hline
\end{tabular}


Table 4 Estimated distribution parameters using LMO.

\begin{tabular}{ccccc}
\hline \hline Location & Distribution & Shape $(\mathrm{k})$ & Scale $(\alpha)$ & Location $(\xi)$ \\
\hline \multirow{3}{*}{ Warri } & GEV & 0.12086 & 18.8308 & 136.1651 \\
& GLO & -0.09492 & 14.0044 & 113.4053 \\
& GPA & 0.65323 & 62.2493 & 77.7219 \\
\hline \multirow{3}{*}{ Benin } & GEV & 0.20673 & 12.74016 & 101.6995 \\
& GLO & -0.044234 & 9.8372 & 83.5521 \\
& GPA & 0.83056 & 52.0196 & 59.7076 \\
\hline \multirow{3}{*}{ Calabar } & GEV & 0.011688 & 176.335 & 25.2097 \\
& GLO & -0.16247 & 127.1326 & 17.8836 \\
& GPA & 0.44094 & 83.1857 & 62.6221 \\
\hline \multirow{3}{*}{ PHC } & GEV & -0.064196 & 117.3185 & 21.3112 \\
& GLO & -0.211634 & 101.0992 & 14.6343 \\
& GPA & 0.301328 & 66.5966 & 42.8083 \\
\hline \multirow{3}{*}{ Uyo } & GEV & -0.1645 & 125.9911 & 27.3225 \\
& GLO & -0.2796 & 103.9153 & 17.9799 \\
Bayelsa & GPA & 0.1259 & 64.1952 & 40.5663 \\
& GEV & -0.4323 & 125.056 & 37.6603 \\
& GLO & -0.4799 & 97.7998 & 22.1987 \\
\hline \hline
\end{tabular}

The parameters presented in Table 4 were applied to the relevant quantile function given in Table 1 in order to estimate the predicted annual maximum daily rainfall records based on LMO using the threeprobability distributions viz., GEV, GLO and GPA. Using the observed and predicted rainfall records, five selected GoF statistics were then applied in order to determine the best fit probability distribution model. The estimated parameters of the selected GoF statistics are presented in Table 5.

Based on the result of Table 5, the distribution with the least RMSE, least RRMSE, lowermost MADI, smallest MAE and highest PPCC was assigned a score of 3, the next was given the score 2, while the worst was given the score 1 . The score of each distribution was obtained by summing the individual point scores and the distribution with the highest total point score was selected as the best fit distribution. Result of the scoring and ranking procedure is presented in Table 6.

Table 5 Computed values of GoF statistics.

\begin{tabular}{ccccccc}
\hline \hline Location & Distribution & RMSE & RRMSE & MADI & MAE & PPCC \\
\hline \multirow{3}{*}{ Warri } & GEV & 31.3074 & 0.32105 & 0.27967 & 47.99265 & 0.999595 \\
& GLO & 3.86371 & 0.03985 & 0.00291 & 14.13908 & 0.999961 \\
& GPA & 6.68388 & 0.07187 & 0.00278 & 17.84667 & 0.999829 \\
\hline \multirow{3}{*}{ Benin } & GEV & 21.4954 & 0.28078 & 0.23757 & 31.1775 & 0.999602 \\
& GLO & 8,0531 & 0.06432 & 0.04035 & 41.331 & 0.999858 \\
& GPA & 9.05434 & 0.07893 & 0.00584 & 44.826 & 0.999729 \\
\hline \multirow{3}{*}{ Calabar } & GEV & 65.9314 & 0.5844 & 0.5366 & 77.0051 & 0.999729 \\
& GLO & 6.9636 & 0.06087 & 0.03959 & 14.40959 & 0.999857 \\
& GPA & 6.43119 & 0.06266 & 0.000106 & 18.7236 & 0.999832 \\
\hline \multirow{3}{*}{ PHC } & GEV & 32.1616 & 0.3485 & 0.3258 & 44.2466 & 0.999838 \\
& GLO & 7.7191 & 0.0791 & 0.0621 & 17.4944 & 0.999888 \\
& GPA & 6.2902 & 0.0416 & 0.00296 & 23.0373 & 0.999862 \\
\hline \multirow{3}{*}{ Uyo } & GEV & 47.5855 & 0.4973 & 0.4702 & 71.5865 & 0.999712 \\
& GLO & 13.8794 & 0.1279 & 0.1110 & 28.2935 & 0.999649 \\
& GPA & 11.3530 & 0.0598 & 0.00355 & 63.0729 & 0.999551 \\
\hline \multirow{3}{*}{ Bayelsa } & GEV & 88.7732 & 0.9017 & 0.8487 & 195.351 & 0.9963 \\
& GLO & 31.6674 & 0.3194 & 0.2807 & 69.576 & 0.9978 \\
& GPA & 14.9249 & 0.0756 & 0.0138 & 74.132 & 0.9993 \\
\hline \hline
\end{tabular}


Table 6 Scoring and ranking scheme for selected probability distribution models

\begin{tabular}{|c|c|c|c|c|}
\hline \multirow[t]{2}{*}{ Location } & \multirow[t]{2}{*}{ Test Criteria } & \multicolumn{3}{|c|}{ Distribution Scoring } \\
\hline & & GEV & GLO & GPA \\
\hline \multirow{6}{*}{ Warri } & RMSE & 1 & 3 & 2 \\
\hline & RRMSE & 1 & 3 & 2 \\
\hline & MADI & 1 & 2 & 3 \\
\hline & MAE & 1 & 3 & 2 \\
\hline & PPCC & 1 & 3 & 2 \\
\hline & Total Score/ Rank & $5(3 \mathrm{rd})$ & $14(1 \mathrm{st})$ & $11(2 \mathrm{nd})$ \\
\hline \multirow{6}{*}{ Benin } & RMSE & 1 & 3 & 2 \\
\hline & RRMSE & 1 & 3 & 2 \\
\hline & MADI & 1 & 2 & 3 \\
\hline & MAE & 3 & 2 & 1 \\
\hline & PPCC & 1 & 3 & 2 \\
\hline & Total Score/ Rank & 7 (3rd) & $13(1 \mathrm{st})$ & $10(2 \mathrm{nd})$ \\
\hline \multirow{6}{*}{ Calabar } & RMSE & 1 & 2 & 3 \\
\hline & RRMSE & 1 & 3 & 2 \\
\hline & MADI & 1 & 2 & 3 \\
\hline & MAE & 1 & 3 & 1 \\
\hline & PPCC & 1 & 3 & 2 \\
\hline & Total Score/ Rank & $5(3 \mathrm{rd})$ & $13(1 \mathrm{st})$ & $11(2 \mathrm{nd})$ \\
\hline \multirow{6}{*}{ PHC } & RMSE & 1 & 2 & 3 \\
\hline & RRMSE & 1 & 2 & 3 \\
\hline & MADI & 1 & 2 & 3 \\
\hline & MAE & 1 & 3 & 2 \\
\hline & PPCC & 1 & 3 & 2 \\
\hline & Total Score/ Rank & $5(3 \mathrm{rd})$ & $12(2 \mathrm{nd})$ & $13(1 \mathrm{st})$ \\
\hline \multirow{6}{*}{ Uyo } & RMSE & 1 & 2 & 3 \\
\hline & RRMSE & 1 & 2 & 3 \\
\hline & MADI & 1 & 2 & 3 \\
\hline & MAE & 1 & 3 & 2 \\
\hline & PPCC & 3 & 2 & 1 \\
\hline & Total Score/ Rank & $7(3 \mathrm{rd})$ & $11(2 \mathrm{nd})$ & $12(1 \mathrm{st})$ \\
\hline \multirow{6}{*}{ Bayelsa } & RMSE & 1 & 2 & 3 \\
\hline & RRMSE & 1 & 2 & 3 \\
\hline & MADI & 1 & 2 & 3 \\
\hline & MAE & 1 & 3 & 2 \\
\hline & PPCC & 1 & 2 & 3 \\
\hline & Total Score/ Rank & $5(3 \mathrm{rd})$ & $11(2 \mathrm{nd})$ & $14(1 \mathrm{st})$ \\
\hline
\end{tabular}

Based on the result of Table 6 , the following inferences and decisions were made:

(a) GLO with the highest total score of 14 was selected as the best probability distribution model for analyzing annual maximum daily rainfall series in Warri;

(b) GLO with the highest total score of 13 was selected as the best probability distribution model for analyzing annual maximum daily rainfall series in Calabar;

(c) GPA with the highest total score of 13 was selected as the best probability distribution model for analyzing annual maximum daily rainfall series in Port Harcourt; and

(d) Generalized Pareto probability distribution (GPA) with the highest total score of 12 was selected as the best probability distribution model for analyzing annual maximum daily rainfall series in Uyo.

The quantile estimates (Qt) based on 2, 5, 10, 25, 50, 100, 200 and 500 years return period was obtained based on LMO procedure using the best fit probability distribution model for each location. A graphical plot of the predicted annual maximum daily precipitation for the selected return period using the best fit probability distribution model is presented in Fig. 3. Result of Fig. 3 can be employed to predict the rainfall magnitude for selected return periods which is a key parameter needed for the design of hydraulic structures and other hydrological studies. Using the best-fit model, the following rainfall magnitude presented in Table 7 were estimated. 

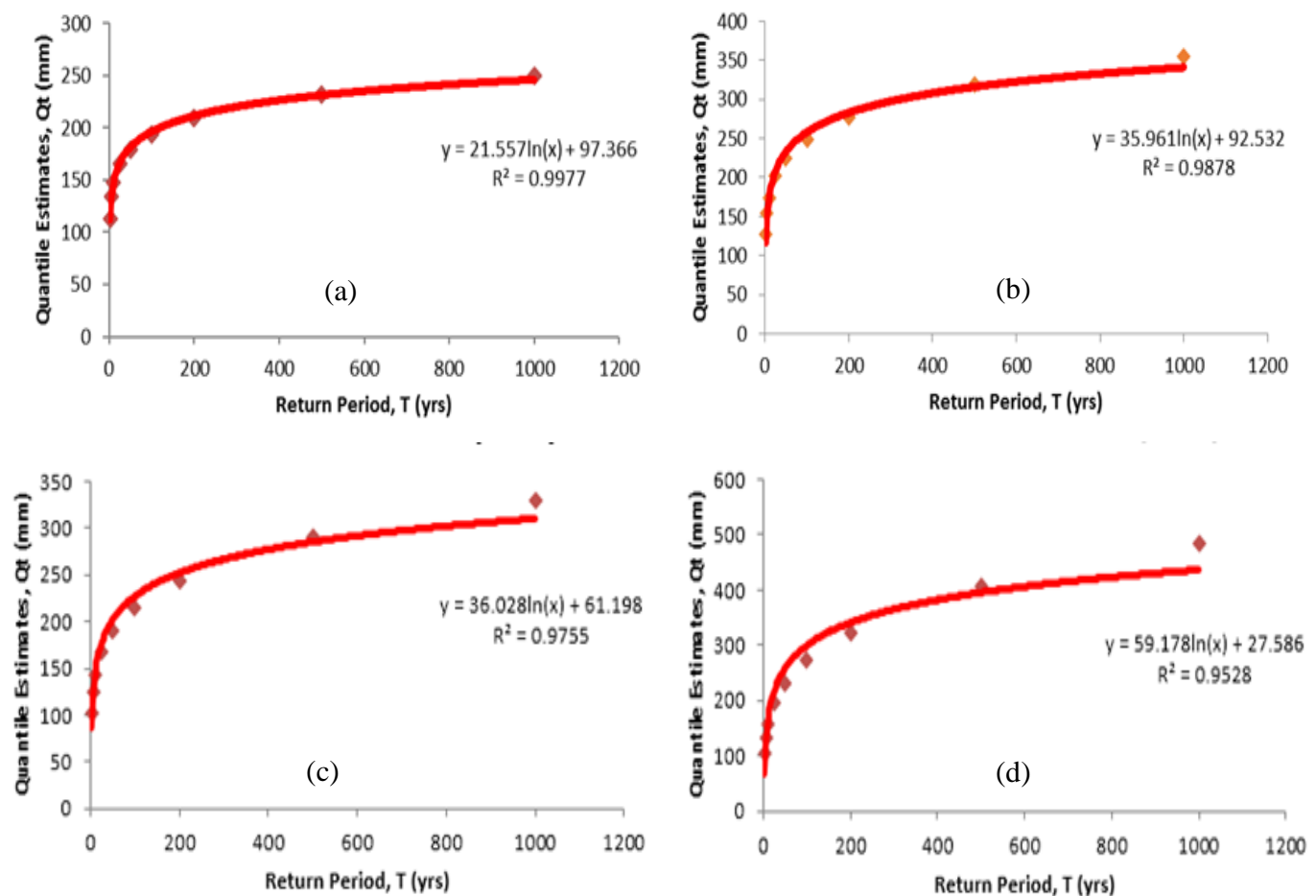

Fig. 3 Predicted precipitation values for selected return periods: (a) GLO for Warri, (b) GLO for Calabar, (c) GPA for Port Harcourt, and (d) GPA for Uyo.

Table 7 Estimated rainfall magnitude $(\mathrm{mm})$ for selected return periods.

\begin{tabular}{ccccc}
\hline \hline Return Period $(\mathrm{y})$ & Warri & Calabar & Port Harcourt & Uyo \\
\hline 2 & 113.41 & 127.13 & 101.10 & 103.92 \\
5 & 134.15 & 154.94 & 124.68 & 134.36 \\
10 & 147.62 & 174.36 & 142.04 & 158.48 \\
25 & 165.35 & 201.53 & 167.43 & 195.98 \\
50 & 179.34 & 224.21 & 189.53 & 230.52 \\
100 & 194.06 & 249.29 & 214.82 & 272.01 \\
200 & 209.71 & 277.18 & 243.93 & 322.10 \\
500 & 231.95 & 319.08 & 289.46 & 404.90 \\
1000 & 250.07 & 355.14 & 330.21 & 483.15 \\
\hline \hline
\end{tabular}

\section{Conclusion}

The focus of the study was to carry out a comprehensive rainfall frequency analysis for some selected stations within the south-south geopolitical zone of Nigeria. Results of the study have shown that only two of the selected probability distribution models (GLO and GPA) are the best-fit and can be utilized to predict the rainfall return levels at the stations. In addition, the study has also revealed that $\mathrm{L}-$ Moments and $\mathrm{L}-$ Moment ratios are key indicators for the analysis of hydrological data, which can subsequently be employed for estimating the parameters of any probability distribution model. It is recommended that the study be extended to other stations in order to clearly understand the probability distribution model that best describe the rainfall pattern.

\section{Conflict of Interests}

The authors declare that there is no conflict of interests regarding the publication of this paper. 


\section{References}

[1] J. R. M. Hosking, "L-Moments: analysis and estimation of distributions using linear combinations of order statistics," Journal of the Royal Statistical Society, Series B, vol. 52, pp. 105-124, 1990.

[2] G. L. S. K. Chaitanya, "Regional flood frequency analysis using parametric estimation method," National Conference on Water, Environment \& Society, 30 ${ }^{\text {th }}$ - 31st July, Hyderabad, India, 2015, pp. 3-7.

[3] J. O. Ehiorobo, and O. C. Izinyon, "Flood frequency analysis of Oshun River in Asejire dam site, Nigeria," Journal of Earth Science and Engineering, vol. 3, pp. 292-300, 2013.

[4] N. Vivekanandan, "Flood frequency analysis using method of moments and L-moments of probability distribution," Cogent Engineering, vol. 2, no. 1, pp. 1-10, 2015.

[5] M. A. Sharma, and J. B. Singh, "Use of probability distribution in rainfall analysis," New York Science Journal, vol. 3, no. 9, pp. 40-49, 2010.

[6] I. R. Ilaboya, and E. A. Otuaro, "Analysis of maximum rainfall series in Benin city using generalized extreme value (gev), generalized logistics (glo) and generalized pareto (gpa) distribution by method of L-moment," Journal of Civil and Environmental Systems Engineering, vol. 17, no. 1, pp. 100-112, 2019.

[7] J. R. M. Hosking, and J. R. Wallis, "Regional frequency analysis: an approach based on L-moments," Cambridge: Cambridge University Press, 1997.

[8] O. C. Izinyon, and J. O. Ehiorobo, "L-moments method for flood frequency analysis of River Owan at Owan in Benin Owena river basin in Nigeria," Current Advances in Civil Engineering, vol. 3, no. 1, pp. 1-10, 2015.

[9] J. M. Landwehr; N. C. Matalas, and J. R. Wallis, "Probability weighted moments compared with some traditional techniques in estimating Gumbel parameters and quantiles," Water Resources Research, vol. 15, no. 5, pp. 1055-1064, 1979.

[10] U. N. Ahmad, A. Shabri, and Z. A. Zakaria, "Flood frequency analysis of annual maximum flows using L-moments and TL-moments approach," Applied Mathematics Sciences, vol. 5, no. 5, pp. 243 -253, 2011

[11] F. E. Eregno, "Regional flood frequency analysis using L-moment in the tributaries of Upper Blue Nile River, South Western Ethiopia," Merit Journal of Engineering, Pure and Applied Sciences, vol. 2, no. 2, pp. 12-21, 2014.

[12] G. Sanjib, K. R. Manindra, and C. B, "Soma determination of the best fit probability distribution for monthly rainfall data in Bangladesh," American Journal of Mathematics and Statistics, vol. 6, no. 4, pp. 170-174, 2016.

[13] H. Herlina, "Modeling extreme rainfall with gamma-pareto distribution," Applied Mathematical Sciences, vol. 9, no 121, pp. 6029-6039, 2015

[14] Center for Ecology and Hydrology (CEH), FLOODS version 1.1, Regional flood frequency analysis software manual, Water Resources section, CEH Wallingford, U.K., 2001.

[15] T. S. Gubareva, and B. I. Gartsman, "Estimating distribution parameters of extreme hydrometeorological characteristics by L-moment method," Water Resources, vol. 37, no. 4, pp. 437-445, 2010.

[16] J. U. Emeh, A. J. Isangedighi, P. Asuquo, I. Kalu, and A. M. Ogaboh, "Curriculum review: reactions from education stakeholders in south-south states of Nigeria," Global Journal of Human Social Science, vol. 11, no. 2, pp. 33-42, 2011.

[17] D. Raes, P. Willens, and F. Gbaguidi, "Rainbow - a software package for hydrometeorological frequency analysis and testing the homogeneity of historical data sets," Proceedings of the 4th Int. Workshop on Sustainable Management of Marginal Drylands, 27 - 30 January, Islamabad, Pakistan, 2006, pp. 41-55.

[18] H. Maleki-Nezhad, "Regional flood frequency analysis using L-moments approach," 7th Int. Congress on Civil Engineering, Tehran Iran, May 8-10, 2006, pp. 1-7. 